\title{
DNA INDEX AND \% S PHASE FRACTION IN POSTERIOR UVEAL MELANOMA: A 5 YEAR PROSPECTIVE STUDY OF FRESH TISSUE USING FLOW CYTOMETRY
}

\author{
R. P. S. RICHARDSON ${ }^{1}$, L. LAWRY ${ }^{2}$, R. C. REES ${ }^{2}$ and I. G. RENNIE ${ }^{1}$ \\ Sheffield
}

\begin{abstract}
SUMMARY
In many different solid tumours the DNA content of cells has been reported to be associated with malignancy. With one exception, studies using flow cytometry to estimate cellular DNA in uveal melanoma have used archival material. We report the findings of a prospective study using fresh uveal melanoma where the DNA index (DI) and percentage of cells in S phase (\%SPF) have been determined by flow cytometry in 51 patients with a minimum follow-up of 5 years. Fortyone $(80 \%)$ of the tumours were large, $9(18 \%)$ were medium and only 1 was small. Eight $(16 \%)$ were epithelioid tumours, $41(80 \%)$ were mixed cell and only $\mathbf{2}$ were spindle B cell tumours. Twenty-seven tumours were diploid, of which $10(37 \%)$ developed metastases. of the 24 aneuploid tumours, metastases developed in 6 $(25 \%)$. The median \%SPF was significantly reduced in patients with diploid tumours compared with aneuploid tumours $(p<0.0001)$, but there were no significant differences in \%SPF between tumours associated with or without metastatic disease. The DI and \%SPF were not significantly associated with the operation performed, cell morphology, tumour size or location. Neither \%SPF nor aneuploidy was associated with a poor prognosis. Our results suggest that the estimation of DI or \%SPF by flow cytometry is of little value in predicting survival from uveal melanomas after a minimum follow-up of 5 years.
\end{abstract}

Uveal malignant melanoma is the commonest primary ocular tumour in adults, with up to $50 \%$ of patients eventually dying from metastatic-related disease. ${ }^{1}$ Clinical and histological prognostic factors for patient survival have included an anterior tumour

From: ${ }^{1}$ University Department of Ophthalmology and Orthoptics and ${ }^{2}$ Institute of Cancer Studies, Sheffield University, S. Yorks, UK.

Correspondence to: Mr R. P. S. Richardson, University Department of Ophthalmology and Orthoptics, Royal Hallamshire Hospital, Glossop Road, Sheffield S10 2JF, S. Yorks, UK. location, tumour size, scleral or optic nerve invasion, extra-scleral spread, an epithelioid or mixed cellular composition, a lymphocytic infiltrate, and the vascular pattern of the tumour. ${ }^{2-5}$ Nuclear and nucleolar phenotypes also have prognostic value. ${ }^{6,7}$

Studies of DNA content of a variety of tumours have indicated that in some the presence of nondiploid (aneuploid) cells carries a poor prognosis. ${ }^{8,9}$ Flow cytometry studies of cellular DNA in uveal melanoma have, with one exception, ${ }^{10}$ used archival material and as yet no consistent pattern of either proliferation or aneuploidy has been associated with patient survival. ${ }^{10-16}$ We have previously reported on the DNA index (DI) and the percentage of proliferating cells in 19 posterior uveal melanomas in which no relation between cell turnover and tumour size or anatomical location could be determined. ${ }^{10}$ We now report the results of flow cytometry on tumours from 51 consecutive patients with a minimum follow-up of 5 years.

\section{Patients}

Fifty-one patients with a diagnosis of posterior uveal melanoma referred to the Ocular Oncology Unit between February 1985 and 1990 were enrolled after informed consent had been obtained. All patients were subject to a full medical examination including liver function tests, abdominal ultrasound, chest radiograph, and orbital and abdominal CT scans. None had clinical, radiological or biochemical evidence of metastatic disease at presentation. Ocular examination included visual acuity, tonometry, external ocular examination, slit-lamp biomicroscopy and indirect ophthalmoscopy. The tumour was measured by A- and B-mode ultrasonography (Cooper-Vision) and intravenous fluorescein angiography was performed. The primary management of 
these patients was by either enucleation or local resection. The patients were followed up at 3 and 9 month intervals; follow-up included indirect ophthalmoscopy, fundus photography, B-mode ultrasonography and liver function tests. The cause of death was obtained from the death certificate after direct contact with the general practitioner.

\section{Tumour Biopsy}

Immediately following enucleation the globe was bisected, the overlying retina was removed to expose the tumour and samples were taken for flow cytometry. Tumours removed by local resection were placed in buffered saline until the operation was completed before samples were taken. The globe with residual tumour or locally resected tumour was placed in 3\% glutaraldehyde solution and processed for - routine histological examination. Tumour cell type was classified as spindle, epithelioid or mixed, and the tumour size was estimated from ultrasound readings and microscope slides, measured using a graticule with a $\times 1$ objective. The tumours were defined as small $(<10 \mathrm{~mm}$ largest tumour diameter [LTD] or less than $3.0 \mathrm{~mm}$ elevation), medium (10.0 to $<15 \mathrm{~mm}$ LTD or $3.0-5.0 \mathrm{~mm}$ elevation) or large ( $>15.0 \mathrm{~mm}$ LTD or greater than $5.0 \mathrm{~mm}$ elevation).

\section{Flow Cytometry}

Tumour samples were placed in RPMI transport medium (Biological Industries, Scotland) supplemented with $10 \%$ fetal bovine serum (FBS, Gibco, Scotland). The tumour samples were cut into $1 \mathrm{~mm}$ cubes and digested with $0.025 \%$ type 2 collagenase (Sigma UK) together with $0.05 \%$ pronase E (Sigma UK) and $0.5 \mathrm{mM}$ dithiothreitol (Sigma UK) in phosphate-buffered saline under rotation at $37^{\circ} \mathrm{C}$ for 2 hours. The cell suspension was washed twice with RPMI supplemented with $10 \%$ FBS, centrifuged at $390 \mathrm{~g}$ for 10 minutes and held on ice at $4^{\circ} \mathrm{C}$.

Cell suspensions were filtered through a $50 \mu \mathrm{m}$ mesh prior to DNA staining with mithrymicin $(93.6 \mathrm{mg} / \mathrm{ml})$ and ethidium bromide $(37.5 \mathrm{mg} / \mathrm{ml})$ (both from Sigma UK) as previously described. ${ }^{10}$ Cell suspensions were analysed using a FACS 420 flow cytometer with an accessory Consort 30 computer using a $457 \mathrm{~nm}$ excitation laser and measuring the emitted fluorescence through a $530 \mathrm{~nm}$ band-pass filter with a band width of 30 $\mathrm{nm}$. A minimum of 10000 cells were analysed for each sample. The data were converted to a PC format and cell cycle measurements were calculated using Multicycle software. The ploidy of the sample was calculated using the equation:

DNA index $=\frac{\text { G0/G1 peak channel (tumour cells) }}{\text { G0/G1 peak channel (normal cells) }}$

using each patient's lymphocytes to determine the diploid standard. Scatter analysis gates were used to minimise histogram contamination by cellular debris and cell clumps. The quality of the sample was assessed by the coefficient of variation $(\mathrm{CV})$ of the G0/G1 peak. CVs of less than 8.0 were considered good quality. A CV greater than 8.0 was considered poor quality and attempts were made to improve the preparation of the sample, which was then re-stained and re-analysed. The percentage of cells in S phase (\%SPF) was determined from the sum of the percentages of all cells in S phase from the multicycle analysis.

\section{Statistics}

The median \%SPF values in patients with and without metastases in diploid and aneuploid populations were compared by the non-parametric Mann-Whitney $U$-test. Comparisons were also made of the \%SPF with the operation performed, tumour cell type, location and tumour size.

\section{Patient Details}

\section{RESULTS}

Between February 1985 and December 199151 patients (21 men and 30 women) underwent enucleation or local resection as the primary treatment for posterior uveal melanoma. The median age at presentation was 58.8 years (range 23-87 years). Sixteen patients $(31.4 \%)$ have subsequently died from metastatic-related disease with a median survival of 36.2 months (range 8-68 months) after diagnosis (Table I). Those surviving have a median follow-up of 91.1 months (range 67-130 months).

\section{Tumour Characteristics}

Twenty-seven (53\%) tumours arose from the choroid, $9(18 \%)$ from the ciliary body and in $15(29 \%)$ the anterior margin extended into the ciliary body. Forty-one $(80 \%)$ tumours were classified as large, 9 $(18 \%)$ were medium and 1 was small. Eight $(16 \%)$ tumours were epithelioid, $41(80 \%)$ were mixed cell and 2 were spindle cell $\mathrm{B}$ tumours. There were no metastatic-related deaths in patients with either small or spindle cell tumours.

\section{DNA Index}

Twenty-seven patients $(53 \%)$ had diploid tumours (Fig. 1), of whom $10(37 \%)$ died from metastaticrelated disease by 5 years (Table I). Of the 24 patients with aneuploid tumours, $6(25 \%)$ died from metastatic-related disease. Sixteen of the aneuploid tumours had mixed aneuploid/diploid cell populations (Fig. 2), including four tetraploid and two supratetraploid tumours. Three were hypoploid and 5 were pure aneuploid. The median $\mathrm{CV}$ for the study group was 5.4 (range 3.3-13.0). 
Table I. The DNA index and percentage of cells in the S phase fraction (\%SPF) with morphological details of the tumours which metastasised

\begin{tabular}{|c|c|c|c|c|c|c|c|}
\hline Patient no. & DNA index & $\%$ SPF & Size & Cell & Location & Status & Survival (months) \\
\hline 1 & $1.0+2.0$ & 11.0 & $\mathrm{~L}$ & Mix & $\mathrm{Ch} / \mathrm{CB}$ & Deceased & 8.0 \\
\hline 2 & 3.19 & 3.3 & $\mathrm{~L}$ & Mix & $\mathrm{Ch} / \mathrm{CB}$ & Deceased & 8.6 \\
\hline 3 & $1.0+1.86$ & 6.4 & $\mathrm{~L}$ & Mix & $\mathrm{Ch}$ & Deceased & 9.8 \\
\hline 4 & $1.0+1.7$ & 2.6 & $\mathrm{~L}$ & Mix & $\mathrm{CB}$ & Deceased & 25.2 \\
\hline 5 & $1.8+1.7$ & 4.5 & $\mathrm{~L}$ & Epi & $\mathrm{CB}$ & Deceased & 27.8 \\
\hline 6 & $1.0+1.05$ & 5.0 & $\mathrm{~L}$ & Mix & $\mathrm{Ch} / \mathrm{CB}$ & Deceased & 46.0 \\
\hline 7 & 1.0 & 0.7 & $\mathrm{~L}$ & Mix & $\mathrm{Ch} / \mathrm{CB}$ & Deceased & 14.5 \\
\hline 8 & 1.0 & 3.0 & $\mathbf{M}$ & Epi & $\mathrm{Ch}$ & Deceased & 22.9 \\
\hline 9 & 1.0 & 15.5 & $\mathrm{~L}$ & Mix & $\mathrm{Ch}$ & Deceased & 34.0 \\
\hline 10 & 1.0 & 9.8 & $\mathrm{~L}$ & Mix & $\mathrm{Ch} / \mathrm{CB}$ & Deceased & 38.0 \\
\hline 11 & 1.0 & 0.5 & $\mathrm{~L}$ & Mix & $\mathrm{CB}$ & Deceased & 42.2 \\
\hline 12 & 1.0 & 1.3 & $\mathrm{~L}$ & Mix & $\mathrm{Ch}$ & Deceased & 54.1 \\
\hline 13 & 1.0 & 0.7 & $\mathrm{~L}$ & $\operatorname{Mix}$ & $\mathrm{Ch}$ & Deceased & 55.0 \\
\hline 14 & 1.0 & 1.2 & $\mathrm{~L}$ & Epi & $\mathrm{Ch} / \mathrm{CB}$ & Deceased & 57.0 \\
\hline 15 & 1.0 & 2.8 & $\mathrm{~L}$ & Mix & $\mathrm{Ch}$ & Deceased & 67.5 \\
\hline 16 & 1.0 & 2.0 & M & Mix & Ch & Deceased & 67.8 \\
\hline
\end{tabular}

L, large tumour; M, medium tumour; S, small tumour; Mix, mixed cell tumour; Epi, epithelioid tumour; Ch, choroidal tumour; CB, ciliary body tumour; $\mathrm{Ch} / \mathrm{CB}$, tumour whose anterior margin extends into the ciliary body.

\section{$\% S$ Phase Fraction}

The median \% SPF of all tumours was 3.3\% (range 0.4-33.9\%; Table II). The median \% SPF in diploid tumours was $2.2 \%$ (range $0.4-9.8 \%$ ), and in aneuploid tumours the \%SPF was $9.2 \%$ (range $0.4-33.9 \%)$, which was significantly higher ( $p$.0.0001). The median \% SPF in tumours associated with metastases was $2.9 \%$ (range $0.5-11.0 \%$ ), which was not significantly different from those which did not develop metastases (median 3.5\% range $0.4-33.9 \%)$.

The median \%SPF for epithelioid tumours was $6.55 \%$ (range $1.2-33.9 \%$ ), for mixed tumours was $3.3 \%$ (range $0.4-28.3 \%$ ) and for spindle tumours was $1.85 \%$ (range $1.5-2.2 \%$ ). The median \% SPF for choroidal tumours was $3.5 \%$ (range $0.4-19.5 \%$ ), for

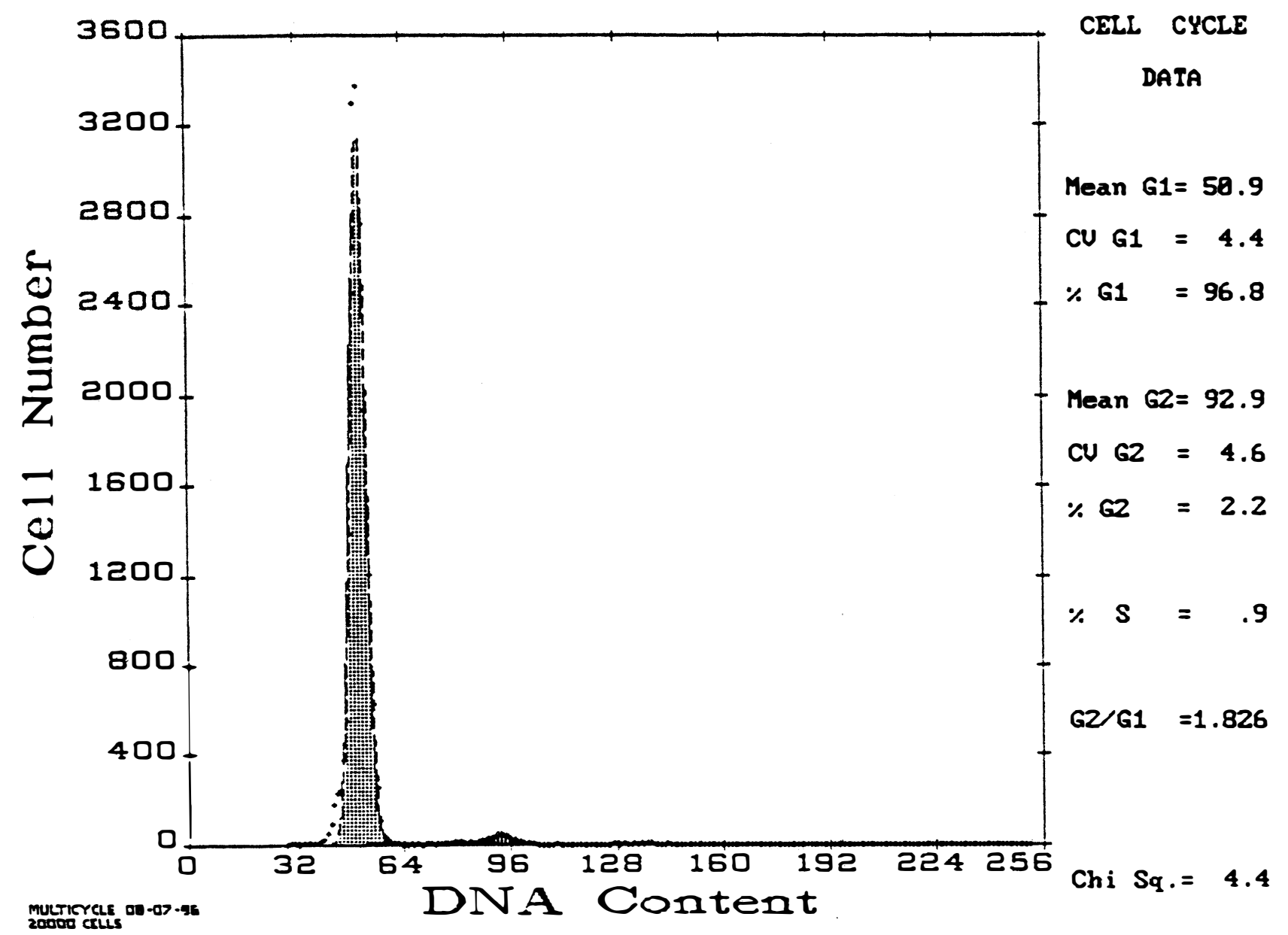

Fig. 1. Flow cytometry histogram from a diploid tumour. 


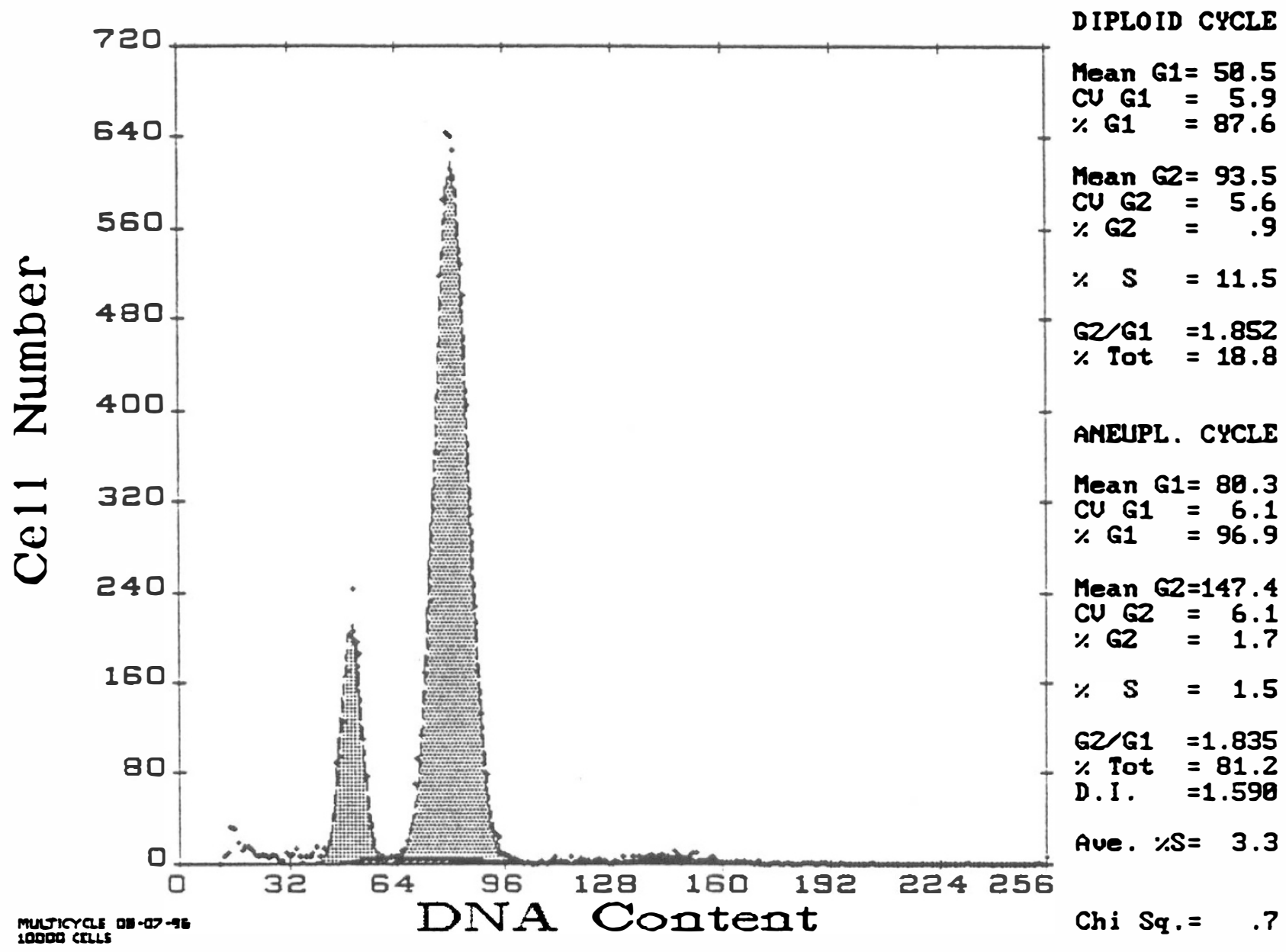

Fig. 2. Flow cytometry histogram from a tumour with a mixed cell population. The diploid population has a peak of fluorescence at channel 50 and the aneuploid population at channel 80.

ciliary body tumours was $2.8 \%$ (range $0.5-33.9 \%$ ) and for those tumours where the anterior margin extended into the ciliary body was 3.3\% (range $0.7-20.7 \%$ ). The median $\% \mathrm{SPF}$ for large tumours was $3.5 \%$ (range $0.4-33.9 \%$ ), for median tumours was $3.0 \%$ (range $0.42-8.6 \%$ ) and for the small tumour was $28.3 \%$. There were no significant differences in median \%SPF between patients undergoing local resection or enucleation, or between tumours based on cell type, location or tumour size.

\section{DISCUSSION}

These results represent the first prospective flow cytometry study of posterior uveal melanoma using fresh tissue and diploid control samples, with a

Table II. The percentage of cells in the S phase fraction (\%SPF) from diploid and aneuploid tumours without metastases

\begin{tabular}{lcccc}
\hline & Median \%SPF & $n$ & Minimum & Maximum \\
\hline All & 3.3 & 51 & 0.4 & 33.9 \\
Metastases & 2.9 & 16 & 0.5 & 11.0 \\
No metastases & 3.5 & 35 & 0.4 & 33.9 \\
DI $=1.0$ & $2.2 *$ & 27 & 0.4 & 9.8 \\
DI $\neq 1.0$ & 9.2 & 24 & 2.6 & 34.5 \\
DI $=1.0$ & & & \\
$\quad$ Metastases & 1.65 & 10 & 0.5 & 9.8 \\
$\quad$ No metastases & 2.2 & 17 & 0.4 & 8.9 \\
DI $\neq 1.0$ & & & 2.6 & 11.0 \\
$\quad$ Metastases & 4.75 & 6 & 1.0 & 3.39 \\
$\quad$ No metastases & 9.45 & 18 & & \\
\hline
\end{tabular}

${ }^{*} p<0.0001$. 
minimum follow-up of 5 years. Previously, aneuploidy has been reported to be associated with decreased survival in posterior uveal melanoma ${ }^{11-16}$ and in other solid tumours. ${ }^{8,9}$ However, in our study aneuploidy was not significantly associated with a poor prognosis. The main conclusion to be drawn is that flow cytometry cannot be used to predict which patients with uveal melanoma will develop metastases with a 5 year minimum follow-up.

Hodge et $a l .{ }^{16}$ described an association between the DI and survival, with a relative risk of death of 3.5 if the tumour was aneuploid, and they found $\%$ SPF of greater than $4 \%$ to be predictive of metastases. Of the 45 tumours analysed, 25 (56\%) were spindle cell B tumours and the remainder were mixed cell tumours. Meecham and Char ${ }^{11}$ were able to determine the DI in 67 tumours, of which 17 $(25 \%)$ were spindle cell tumours. Shapiro et al. ${ }^{13}$ could not relate DI to metastatic death but both large tumours and mixed or epithelioid cell tumours were independent risk factors for metastases. They found that the \%SPF correlated with reduced survival, but they did not state how many of the tumours in the 18 patients with metastases were diploid. Mooy et al. ${ }^{14}$ related aneuploidy to a metastatic outcome, but $38 \%$ of the tumours used were spindle B cell tumours, which comprised half the diploid tumour population. Sixty-six of 146 tumours ( $45 \%$ ) had greater than $25 \%$ non-tumour tissue, which would artefactually increase the proportion of diploid cells, and, moreover, in this sample of patients, 38 had received preenucleation irradiation as part of the primary treatment stratègy. Irradiating tissue causes mitotic delay and results in alterations in chromosome number and structure. ${ }^{17}$ Pseudo-aneuploid appearances can also result from chromatin condensation. ${ }^{18}$ The group of patients who had received preenucleation irradiation had a significantly greater proportion of aneuploidy $\left(\chi^{2} p=0.018\right.$, odds ratio $=$ 2.8 ) and the association of aneuploidy with decreased survival could therefore be due to the radiationinduced alterations or to the systemic side-effects of the radiation.

In this study we found that the median \% SPF was not increased in those tumours which developed metastases compared with non-metastasising tumours, and of interest is the finding that the only small tumour had a \%SPF of $28.3 \%$, the second largest value found. We found that the median $\%$ SPF was greater in epithelioid cell tumours compared with spindle cell tumours, but the small number of spindle cell tumours prevented any statistical interpretation. Likewise, larger tumours had a greater, but not significantly greater, median $\%$ SPF than medium tumours. Aneuploidy was significantly associated with an increased \%SPF but this was independent of the subsequent development of metastases, as the \%SPF was reduced in aneuploid tumours which did develop metastases.

Previous studies have used paraffin-embedded material, which may account for differences in our results. The concordance between the results obtained using fresh tissue and paraffin-embedded tissue to determine DI is only $87 \%$ and paraffinembedded material is less sensitive to small changes in aneuploidy. ${ }^{19}$ Nuclear suspensions prepared from archival material can include a significant proportion of non-tumour tissue ${ }^{14}$ and artefacts may be produced when the section passes through nuclear regions, reducing the DNA content of those cells. In addition, artefacts may be generated by differences in the period of fixation prior to wax embedding, resulting in variable staining efficiencies of the DNA dyes used in flow cytometry. Coleman et $a l .{ }^{15}$ questioned the reliability of the use of paraffin-embedded tissue for flow cytometry when archival material was analysed by both flow cytometry and image analysis. Two of the tumours classified as diploid by flow cytometry were demonstrated to be tetraploid by image analysis. However, only 200 cells are used in image analysis compared with at least 10000 in flow cytometry, techniques are complicated and time-consuming and many preparations are unsuccessful. ${ }^{15}$

Another important difference from previously published studies is the sampling bias introduced by the majority of patients in the present study having medium or large tumours with a high proportion or a pure population of epithelioid cells. Small tumours more frequently have a low epithelioid content and a better prognosis for survival; therefore the present study represents a skewed population of patients who are already at a significant risk of developing metastases.

As the present management of smaller tumours does not often result in tissue being available for histology or other studies including flow cytometry, it is increasingly likely that flow cytometric analysis of uveal melanoma tissue (fresh or paraffin-embedded) will be on larger tumours with 'high-risk' characteristics. Therefore the conclusions drawn from previous analyses by flow cytometry, in which aneuploid uveal melanomas have been associated with a poorer prognosis, may need to be reconsidered, since they were based on the use of paraffin-embedded material and in most studies there was a skewed population of patients with low-risk tumour characteristics.

Non-random chromosomal alterations are significantly associated with posterior uveal melanoma and especially with reduced survival in ciliary body tumours. ${ }^{20,21}$ One limitation of the use of flow cytometry is that it cannot detect deletions or additions of parts of or whole chromosomes, and these smaller alterations in DNA content may be the 
more significant arbitrators of patient survival. Further studies are under way to look for associations between DI and non-random chromosomal alterations.

The authors would like to thank the Yorkshire Cancer Research Campaign for assisting in the funding of this study.

Key words: Uveal melanoma, Survival, Fluorescence-activated cell sorting, Proliferation.

\section{REFERENCES}

1. Gamel JW, McLean IW, McCurdy JB. Biologic distinctions between cure and time to death in 2892 patients with intraocular melanoma. Cancer 1993; 71:2299-305.

2. Paul EV, Parnell L, Fraker M. Prognosis of malignant melanoma of the choroid and ciliary body. Int Ophthalmol Clin 1962;2:387-402.

3. Seddon JM, Albert DM, Lavin PT, Robinson N. A prognostic study of disease-free interval and survival following enucleation for uveal melanoma. Arch Ophthalmol 1983;101:1894.

4. McLean IW, Foster WD, Zimmerman LE. Uveal melanoma: location, size, cell type and enucleation as risk factors in metastases. Hum Pathol 1982;13:123-32.

5. Folberg R, Rummelt V, Parys-van Ginderdeuren R, Hwang T, Woolson RF, Pe'er J, Gruman LM. The prognostic value of tumour blood vessel morphology in primary uveal melanoma. Ophthalmology 1993;100: 1389-98.

6. Gamel JW, McLean IW, Greenberg RA, Seddon JM, Albert DM, Naids RE, Folberg R, Donosa LA. Objective assessment of the malignant potential of intraocular melanomas using standard H\&E-stained microslides. Hum Pathol 1985; 16:689.

7. Gamel JW, McCurdy JB, McLean IW. A comparison of prognostic covariates for uveal melanoma. Invest Ophthalmol Vis Sci 1992;33:1912-22.

8. Sondergaard K, Larsen JK, Moller U, Christensen IJ, Hou-Jensen K. DNA ploidy: characteristics of human malignant melanoma analysed by flow cytometry and compared with histology and clinical course. Virchows Arch Cell Pathol 1983;42:43-52.
9. Friedlander ML, Hedley DW, Taylor IW. Clinical and biological significance of aneuploidy in human tumours. J Clin Pathol 1984;37:961-74.

10. Rennie IG, Rees RC, Parsons MA, Lawry J, Cottam D. Estimation of DNA content in uveal melanomas by flow cytometry. Eye 1989;3:611-7.

11. Meecham WJ, Char DN. DNA content abnormalities and prognosis in uveal melanoma. Arch Ophthalmol 1986;104:1629-9.

12. McMillan J, Char DH, McLean IW, Gamel JW. DNA content analysis of uveal melanoma. Arch Ophthalmol 1989;107:1278.

13. Shapiro BE, Felberg NT, Donoso LA, Ausberger JJ, Gamel J. Flow cytometry of uveal melanomas. Cancer Biochem Biophys 1986;8:235-8.

14. Mooy C, Vissers K, Luyten G, Mulder A, Stijnen T, de Jong P, Bosman F. DNA flow cytometry in uveal melanoma: the effect of pre-enucleation irradiation. $\mathrm{Br}$ J Ophthalmol 1995;79:174-7.

15. Coleman K, Baak JPH, Dorman A, Mullaney J, Curran B, Tiernan D, Farrell M, Fenton M, Leader M. DNA ploidy studies in choroidal melanomas. Am J Ophthalmol 1993;115:376-83.

16. Hodge WG, Duclos AJ, Rocha G, Antecka E, Baines MG, Corriveau C, Brownstein S, Deschennes J. DNA index and $S$ phase fraction in uveal malignant melanomas. Br J Ophthalmol 1995;79:521-6.

17. Denekamp J. Cell kinetics and radiation biology. Int J Radiation Biol 1986;49:357-80.

18. Kubbies M. Flow cytometric DNA-histogram analysis; non-stoichiometric fluorochrome binding and pseudoaneuploidy. J Pathol 1992;167:413-9.

19. Hedley DW, Freidlander ML, Taylor IW, et al. The method for analysis of cellular DNA content of paraffin-embedded pathological material using flow cytometry. J Histochem Cytochem 1985;31:1333-5.

20. Sisley K, Rennie IG, Cottam DW, Potter CW, Rees RC. Cytogenetic findings in six posterior uveal melanomas. Genes Chrom Cancer 1990;2:205-9.

21. Sisley K, Cottam DC, Rennie IG, Parsons MA, Potter AM, Potter CW, et al. Non-random abnormalities of chromosomes 3, 6 and 8 associated with posterior uveal melanoma. Genes Chrom Cancer 1992;5:197-200. 